\title{
Análisis ultraestructural de la formación ósea en relación con el OsteoGen ${ }^{\circledR}$
}

\author{
LOPEZ VALENZUELA C * \\ JAVER MANZUR E ** \\ ARROYO PALACIOS S *** \\ OYARZUN DROGUETT A ****
}

\begin{abstract}
López Valenzuela C, Javer Manzur E, Arroyo Palacios S, Oyarzún Droguett A. Análisis ultraestructural de la formación ósea en relación con el OsteoGen ${ }^{\circledast}$. Av Periodon Implantol. 2002; 14, 1: 29-36.
\end{abstract}

\begin{abstract}
RESUIMEN
El OsteoGen ${ }^{\oplus}$, ha sido profusamente utilizado como material osteoconductor en cirugía periodontal. Sin embargo las características estructurales de la interfase y del hueso neoformado han sido escasamente evaluadas en el ser humano. Con el objeto de estudiar la calidad de la reparación ósea alrededor de OsteoGen ${ }^{\circledR}$, se injertó el material en defectos óseos de dos pacientes. Las biopsias fueron tomadas a los 6 y 12 meses y procesadas para microscopía optica ( MO ) y electrónica de transmisión ( MET ). Los resultados con MO a los seis meses demuestran una clara osteoconducción, lo que se hace notorio a los doce meses practicamente para todas las partículas.
\end{abstract}

\section{PALABRAS CLAVE}

Hueso, periodonto, biomateriales, injerto, osteogénesis, aloplásticos

\section{INTRODUCCIÓN}

El OsteoGen ${ }^{\circledast}$, (HAResorb ${ }^{\circledast}$, Impladent Ltd., Holliswood, NY.), es definido como un material osteoconductor, compuesto de una hidroxiapatita sintética de lenta reabsorción y no cerámica; también de acuerdo al fabricante, su organización cristalina es similar al hueso humano y con ninguna fase que contenga fosfato tricálcico o pirofosfatos inhibidores de mineralización ósea como los encontrado en las HA (hidroxiapatita) cerámicas. Su manufactura permite la obtención de partículas formadas por cristales alargados unidos a un núcleo central que le confiere una gran superficie de contacto e hidrofilia, facilitando la absorción de moléculas de la matriz extracelular, el repoblamiento de células osteoprogenitoras y el sub- secuente depósito de hueso neoformado. Con respecto al OsteoGen ${ }^{\circledast}$, escasas son las investigaciones relativas a su utilización clínica y evaluación histológica especialmente mediante biopsias tanto en humanos como en animales de experimentación. Ricci et al. comprueba histológicamente después de doce semanas de implantar OsteoGen ${ }^{\oplus}$, en tibia de perros una reabsorción de un $80 \%$, un alto potencial osteoconductivo y propiedades químicas que previenen la migración del tejido conectivo (5). Whittaker et al. aprovechando material de autopsia humana post mortem y como reporte de caso, después de seis meses de prueba en cirugías de seno maxilar con implantes osteointegrados, OsteoGen ${ }^{\oplus}$, y DFDBA, comprobaron reabsorción de cristales de OsteoGen ${ }^{\oplus}$, su efecto osteoconductor, y el efecto osteoconductivo

\footnotetext{
* Profesor Adjunto, Curso de Especialización en Periodoncia, Escuela de Graduados, Facultad de Odontología, Universidad de Chile, Santiago de Chile, CHILE.

** CD Práctica privada, Santiago de Chile, CHILE .

*** CD Práctica privada, Santiago de Chile, CHILE.

**** Profesor Asociado, Area de Bioestructura, Facultad de Odontología, Universidad de Chile, Santiago de Chile, CHILE.
} 
del DFDBA (5). Lo mismo concluye Vlassis JM., et al. en un reporte de caso clínico e histológico con materiales similares (OsteoGen ${ }^{\circledast}$, y DFDBA) aplicados en cirugías de seno maxilar (6) y Wagner JR., en reparación de defectos oseos previo a cirugía de implantes endoseos (7). Corsair A., en una evaluación clínica de 24 defectos óseos en 16 pacientes, concluye que habiendo tenido una profundidad promedio inicial de sondaje oseo de $4.47 \mathrm{~mm}$, en la reevaluación después de 4-6 meses, se obtuvo un promedio $2.26 \mathrm{~mm}$ de nuevo hueso, vale decir una ganancia de un $51 \%$ (8). Por último Hurzeler $\mathrm{MB}$ et al., en un estudio del tratamiento de Peri-implantitis en perros Beagle a tres meses con diferentes modalidades de terapia concluyó, que no existen diferencias significativas entre los procedimientos de Regeneración Osea Guiada (ROG) y ROG más injertos (hueso desmineralizado, congelado y desecado y OsteoGen ${ }^{\circledR}$ ), en lo que se refiere a Regeneración Osea tanto desde un punto de vista clínico como histológico $(1,2)$.

Dada la importancia del uso de materiales aloplásticos en cirugía ósea reconstructiva y considerando la escasa información existente relacionada con el mecanismo reparativo de OsteoGen ${ }^{\oplus}$, el presente estudio fue diseñado con el objeto de reexaminar y evaluar a nivel histológico y ultraestructural el comportamiento biológico de OsteoGen ${ }^{\circledR}$, en humanos.

\section{MATERIAL Y MÉTODO}

Los criterios clínicos utilizados para la selección de los dos pacientes involucrados en este estudio fueron los siguentes: ausencia de patologías sistémicas relevantes, ausencia de terapia farmacológica por lo menos durante los últimos seis meses, que presentaran una Periodontitis del Adulto avanzada y generalizada con al menos uno o dos dientes anterosuperiores con indicación de exodoncia por razones protésicas, cuya profundidad al sondaje clínico promedio fuera de al menos $8 \mathrm{~mm}$., movilidad dentaria grado 3 y una reabsorción ósea radiográfica de un $90 \%$. Se eligieron dos pacientes que cumplieron con estos requisitos uno de 40 años (Caso. 1) y el otro 52 años (Caso. 2).

Con el consentimiento asistido e informado de los pacientes y previo tratamiento endodóntico de la pieza elegida, se procedió a efectuar la cirugía a colgajo, que incluyó odontosección coronaria, destartraje supragingival, subgingival, pulido radicular y curetaje de tejidos blandos; enseguida se expusieron los lechos quirúrgicos de los defectos intraóseos preexistentes en los cuales al paciente 1 (diente 8) y al paciente 2 (diente 9) se injertó OsteoGen ${ }^{\circledR}$. Posteriormente se procedió a reposicionar y suturar los colgajos, por primera intención y protegiéndose la zona intervenida con cemento quirúrgico (CoePack $^{\mathrm{TM}}$ GC AMERICA INC. USA). Los cuidados postoperatorios incluyeron: terapia analgésica-antiinflamatoria en base a Ketoralaco, 10 mg cada 12 hrs., por 3 días (Laboratorio CHILE S.A.), así como colutorios de clorhexidina al $0.12 \%$, cada $12 \mathrm{hrs}$., (PerioAid ${ }^{\circledR}$, DENTAID SA, Barcelona, ESPAÑA) por dos semanas.

Las biopsias fueron obtenidas después de seis meses (paciente 1) y doce meses (paciente 2) mediante cirugía de reentrada, ambos especímenes fueron extraídos en bloque, y fijados inmediatamente en una solución de parafomaldehído al 4\% más glutaraldehído al $5 \%$ en buffer fosfato, 0.1 Molar pH 7.4 durante siete días a $4^{\circ} \mathrm{C}$. Las muestras fueron hemiseccionadas con turbina de alta velocidad y refrigeración constante utilizando una fresa troncocónica, de carburo-tungsteno, $\mathrm{N}^{\circ}$ 557(SS-WHITE Burs, Inc, USA). Una de las hemisecciones fue deshidratada en etanoles ascendentes e incluída en L.R. WHITE Resin HARD GRADE ( London Resin Company LTD.), y polimerizada a $60^{\circ} \mathrm{C}$ durante 24 horas. Las muestras fueron cortadas utilizando una sierra diamantada. La otra hemisección fue desmineralizada en EDTA al 10\% en pH 7.4 durante 15 días a $4^{\circ} \mathrm{C}$., postfijada en tetróxido de osmio al $1 \%$ en buffer fosfato 0.1 Molar pH.-7.4, deshidratadas en acetonas ascendentes e incluídas en resina epóxica (Embed 812, EM Sciences). Se realizaron cortes semifinos de 1 micrón de grosor los que se tiñieron con azul de metileno y fucsina básica y cortes ultrafinos de $60 \mathrm{~mm}$ los que se montaron sobre grillas de cobre de 150 mesh. Finalmente los cortes ultrafinos se tiñieron con citrato de plomo y acetato de uranilo, y fueron observados en un Microscopio Electrónico de Transmisión (MET) Zeiss AM-109 operado a $80 \mathrm{kV}$.

\section{RESULTADOS}

\section{Microscopía Optica (MO)}

A los seis meses (Caso 1) podemos observar que las partículas de OsteoGen ${ }^{\odot}$, que rodean la raíz dentaria implantada se encuentran colonizadas por trabéculas de tejido óseo esponjoso laminillar, mientras la interfase entre las partículas de OsteoGen ${ }^{\circledast}$, y la superficie radicular está ocupada por un tejido conectivo fibrilar (figs. 1-2-3). Las zonas del material que no estaban incluidas en la matriz ósea presentan poblaciones celulares de distinta naturaleza entre las cuales fue común encontrar células gigantes multinucleadas en íntimo contacto con el material (fig. 4). A los doce meses (paciente 2) la mayor parte de las partículas implantadas se encuentran inmersas en tejido óseo lamellar. (fig. 5) 


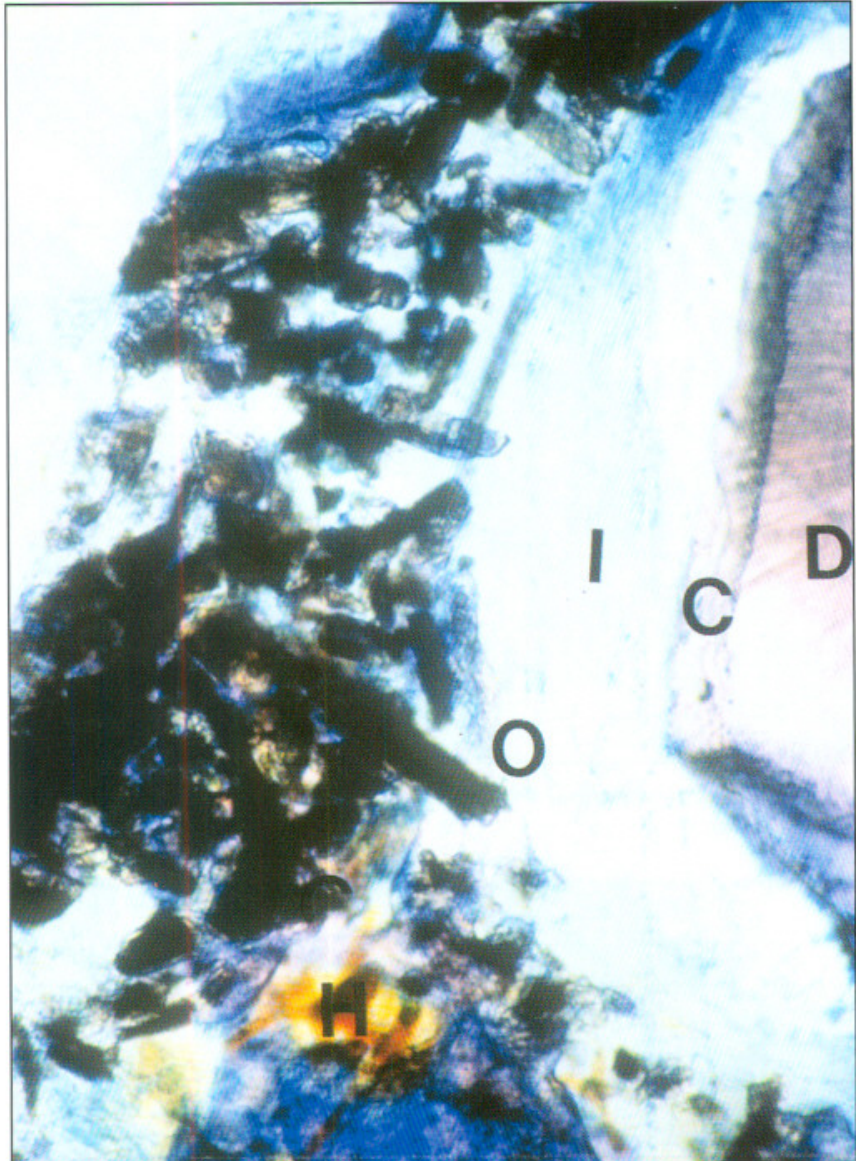

Fig.1: 40x. D: Dentina, C: Cemento, I: Interfase, O: OsteoGen ${ }^{\star}, H:$ Hueso.

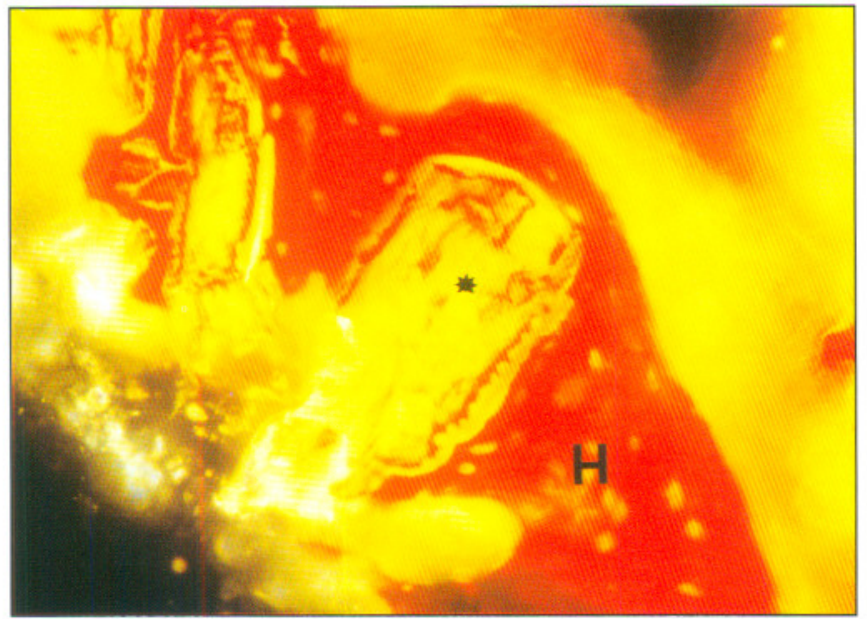

Fig. 3: 400x: O: *, H: Hueso, *: Partículas de OsteoGen ${ }^{\circledR}$, incluidas en una matriz ósea.

Microscopía Electrónica de Transmisión (MET)

Se observa que las partículas están formadas por estructuras fusiformes, sensibles a la desmineralización con EDTA, rodeadas por una matriz electrondensa, finamente granular y de grosores variables. (fig. 6).

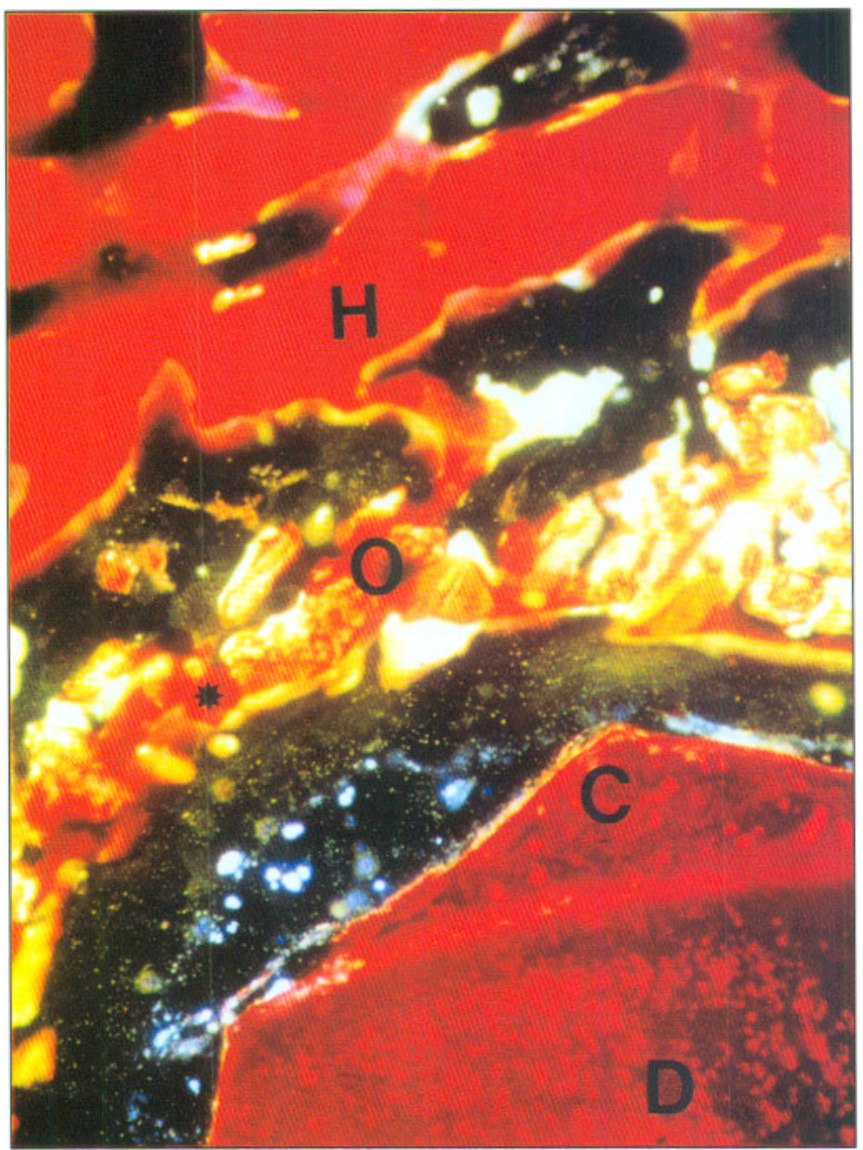

Fig.2: 100x: D: Dentina, C: Cemento, O: OsteoGen ${ }^{\star}$, H: Hueso, *: Trabéculas óseas en contacto directo con las partículas de OsteoGen ${ }^{\circ}$.

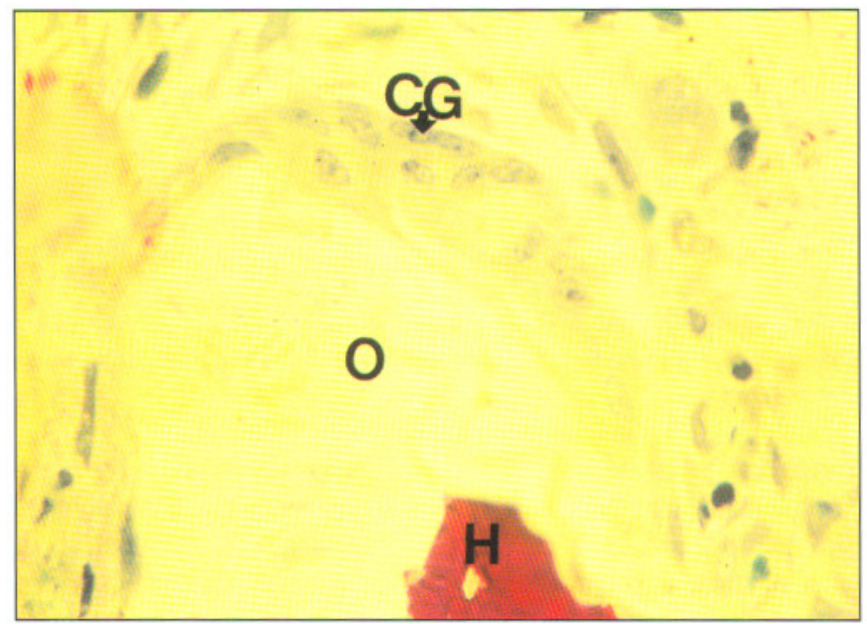

Fig. 4: 1000x: O: OsteoGen ${ }^{\circ}, H$ : Hueso, CG: Célula gigante Multinucleada.

En ambos pacientes se observa que las relaciones entre el tejido óseo y el OsteoGen ${ }^{\oplus}$, pueden adoptar diferentes modalidades dentro de una misma partícula. Es así como la interfase entre el hueso y la partícula puede estar ocupada por una extensa banda de 


\section{AVANCES}

Volumen 14 - N$^{\circ} 1$ - Abril 2002

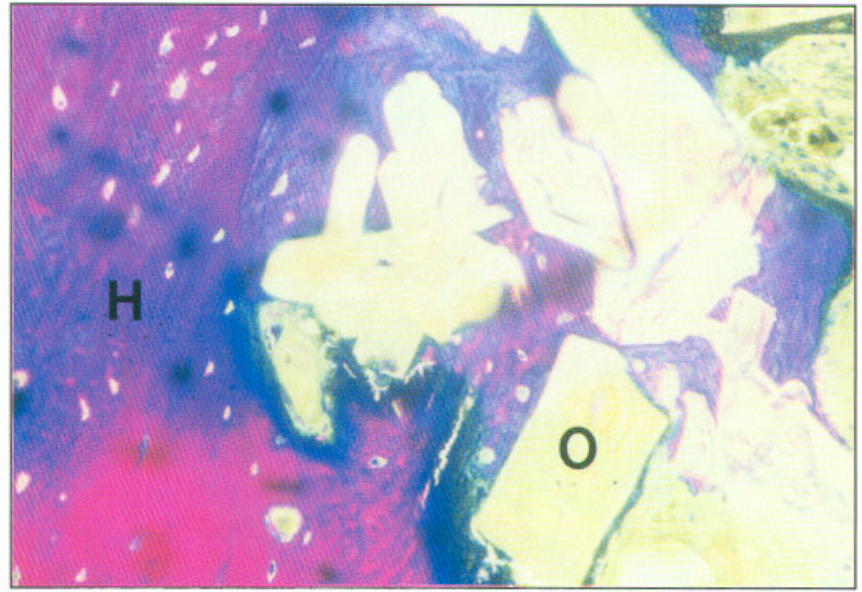

Fig.5: 400x: O: OsteoGen ${ }^{\odot}$, H: Hueso.

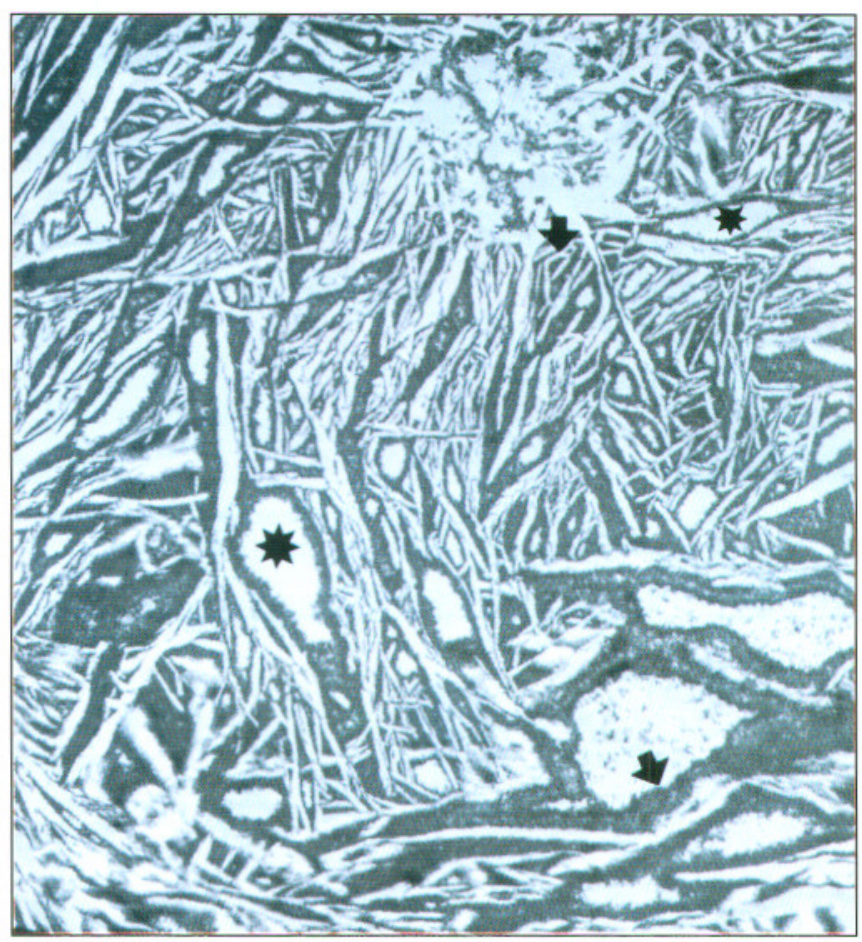

Fig. 6: Aumento original 7000x, *: OsteoGen ${ }^{\star}$, flecha: Matriz electrondensa granular.

material extracelular, de aspecto granular-filamentoso (fig. 7). La transición entre el material interfacial y la partícula está mal delimitada existiendo continuidad con el material que rodea los cristales inorgánicos del

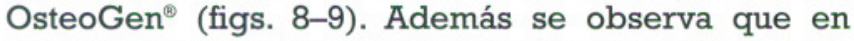
numerosas zonas no existe interfase discernible, produciéndose contacto íntimo entre las fibrillas colágenas del hueso y la partícula (fig. 10). Se detecta fibrillas colágenas del hueso neoformado invadiendo los espacios intercristalinos (figs. 11-12). Por otra parte en otras zonas de la misma o de otra partícula la interfase está ocupada por material extracelular electrondenso compacto de aspecto granular y de menor grosor.

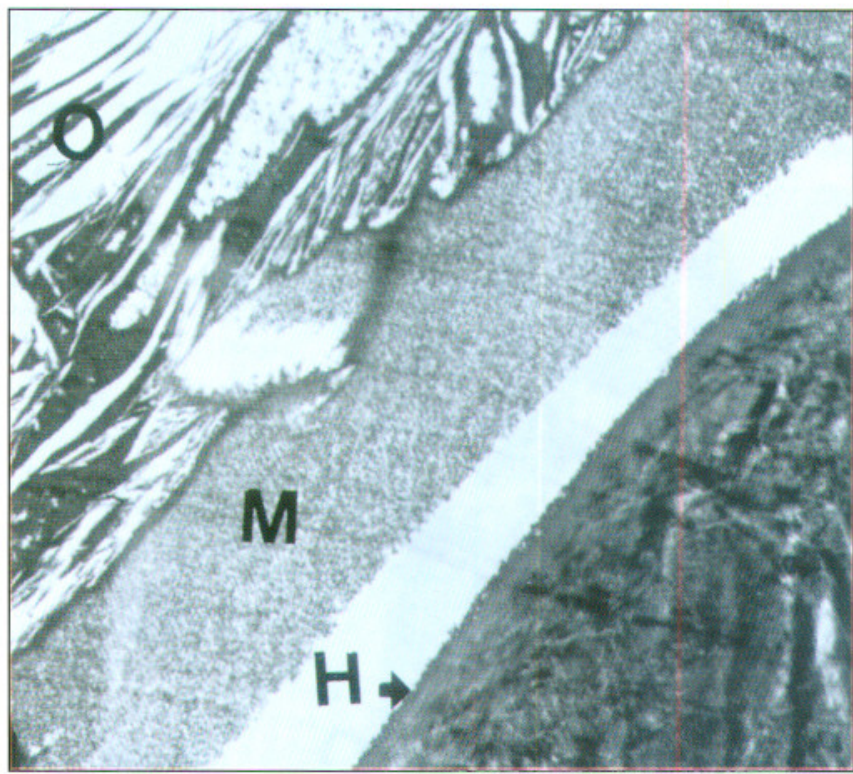

Fig. 1: Aumento original 4400x, O: OsteoGen ${ }^{\circ}$, H: Hueso, M: Material extracelular.

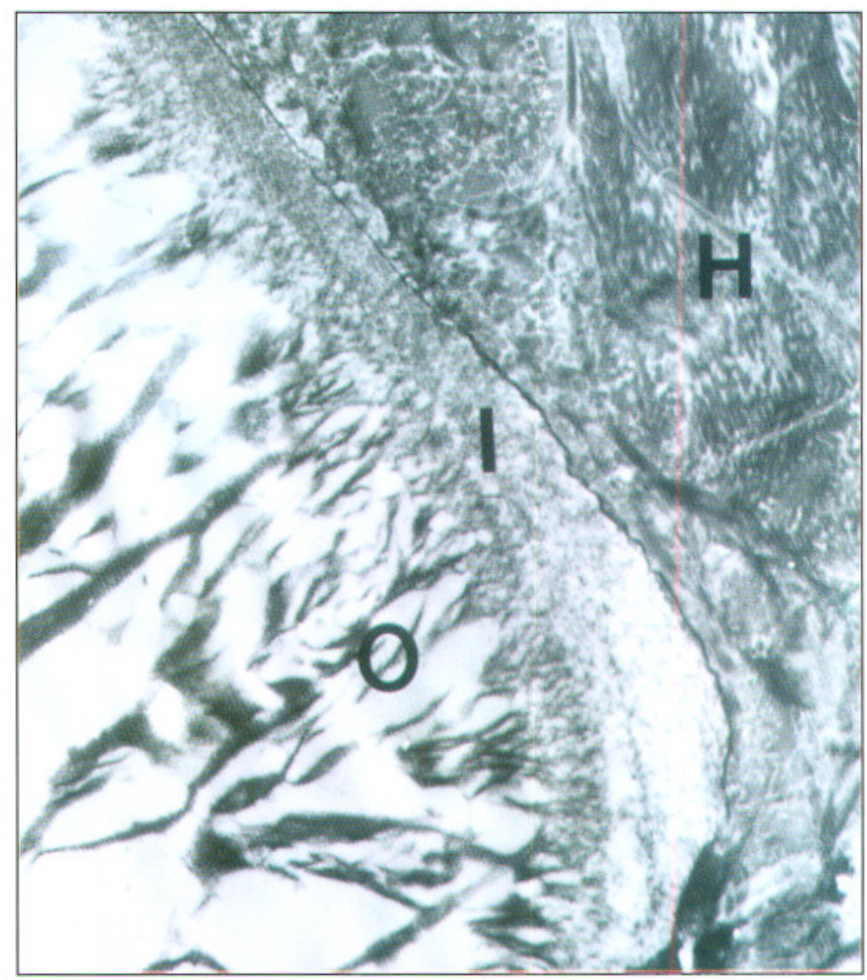

Fig. 8: Aumento original 7000x, O:OsteoGen ${ }^{*}$, H: Hueso, I: Interfase.

\section{DISCUSIÓN}

La osteoconducción, entendida como aquella propiedad de los materiales de injerto que por sus 


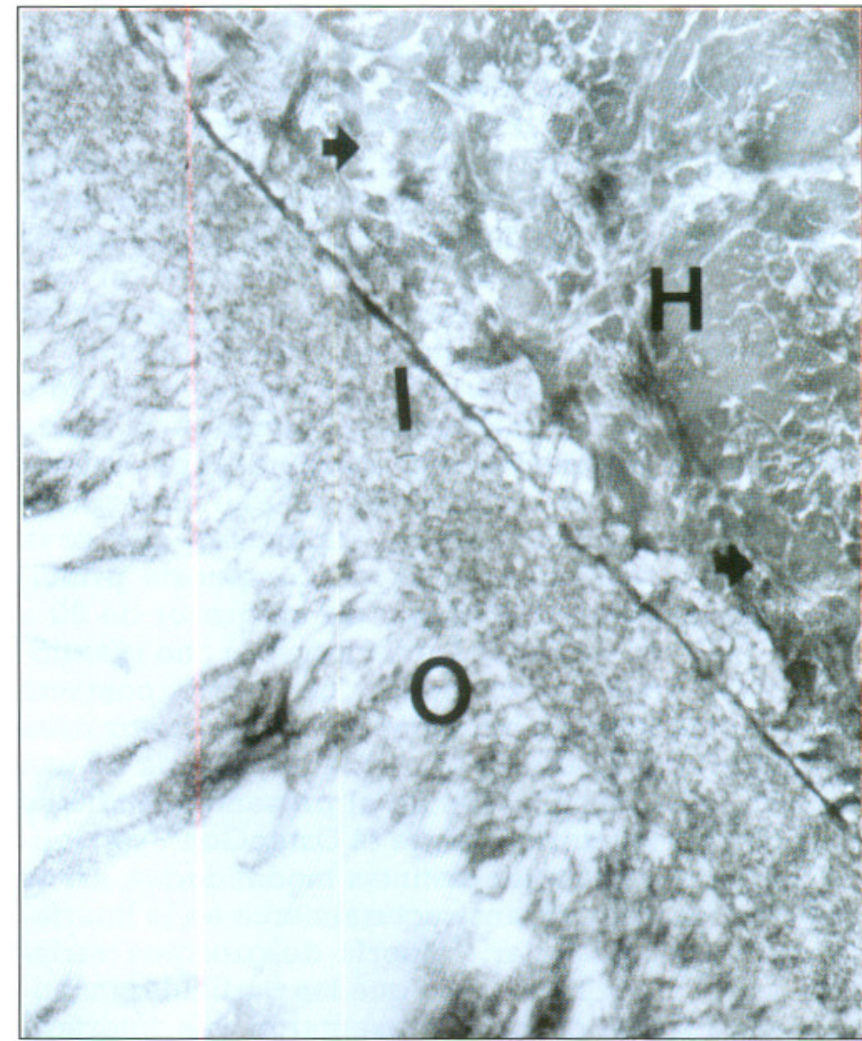

Fig. 9: Aumento original 200000x, O: OsteoGen ${ }^{\circledast}$ H: Hueso, I: Material extracelular de la interfase, flecha: Fibrillas colágenas cortadas transversalmente.

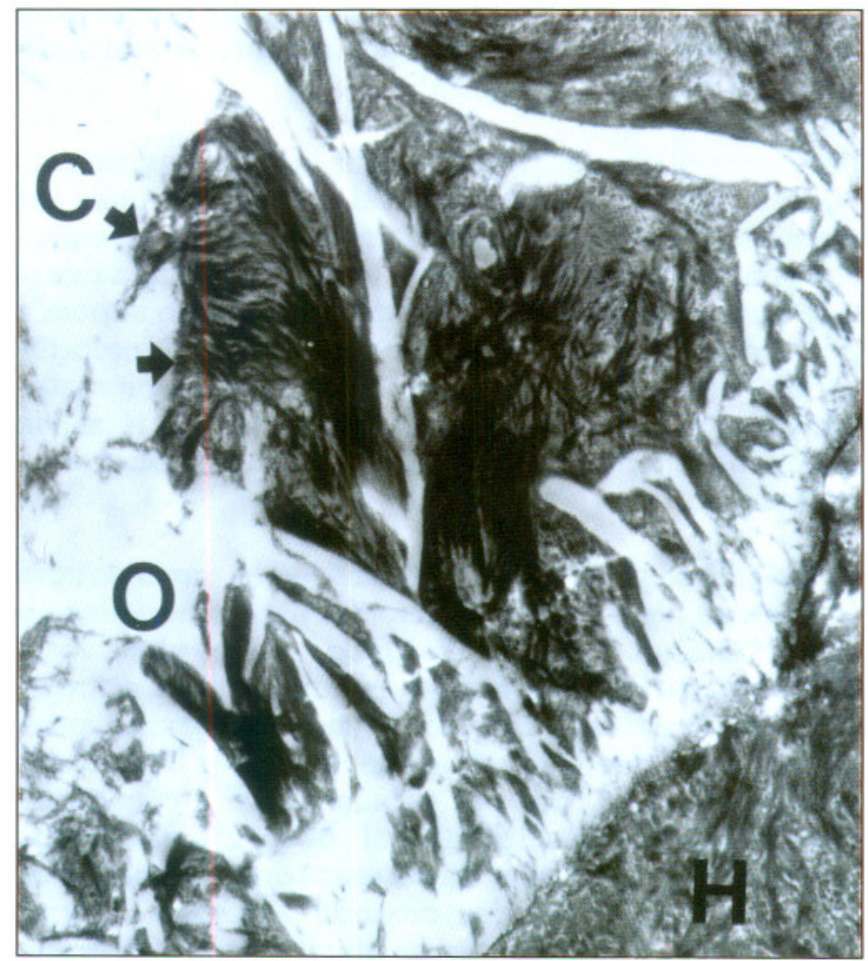

Fig. 11: 7000x: O: OsteoGen ${ }^{\circ}$, H: Hueso, C: Fibrillas colágenas en el interior de las partículas de OsteoGen ${ }^{\varpi}$, (flecha).

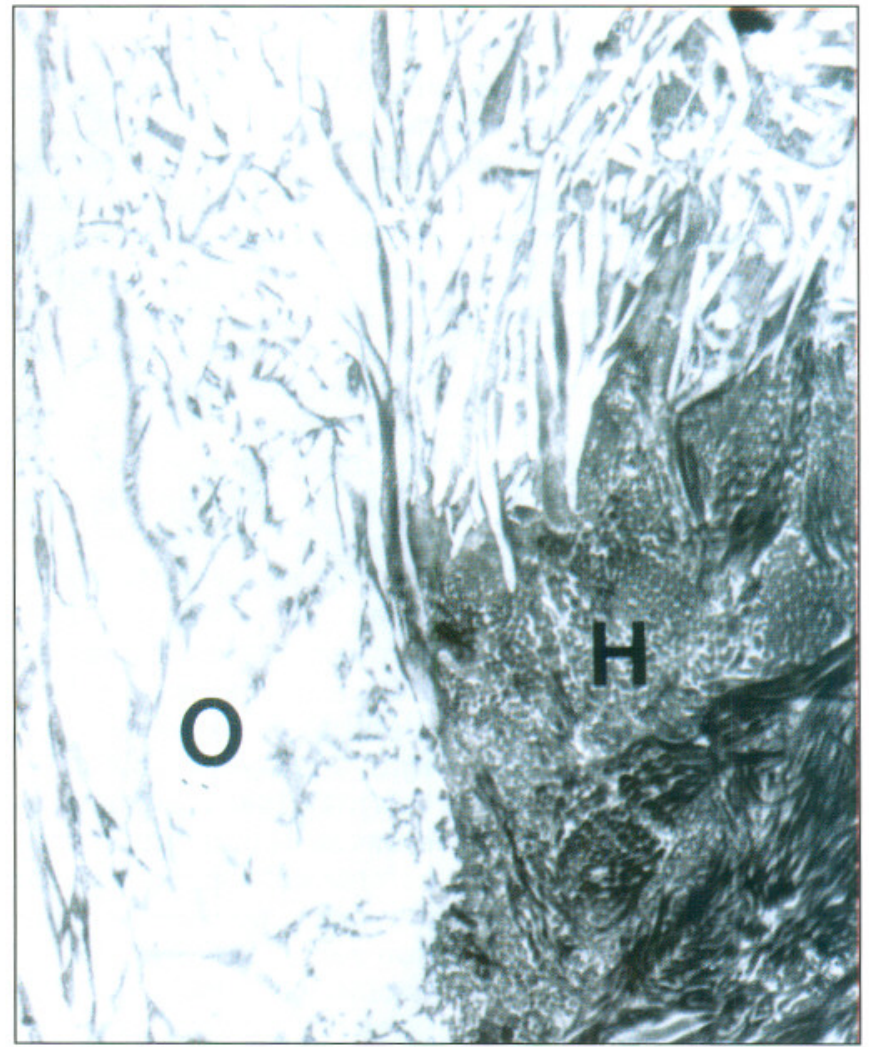

Fig. 10: 7000x: O: OsteoGen ${ }^{\circ}$ H: Hueso.

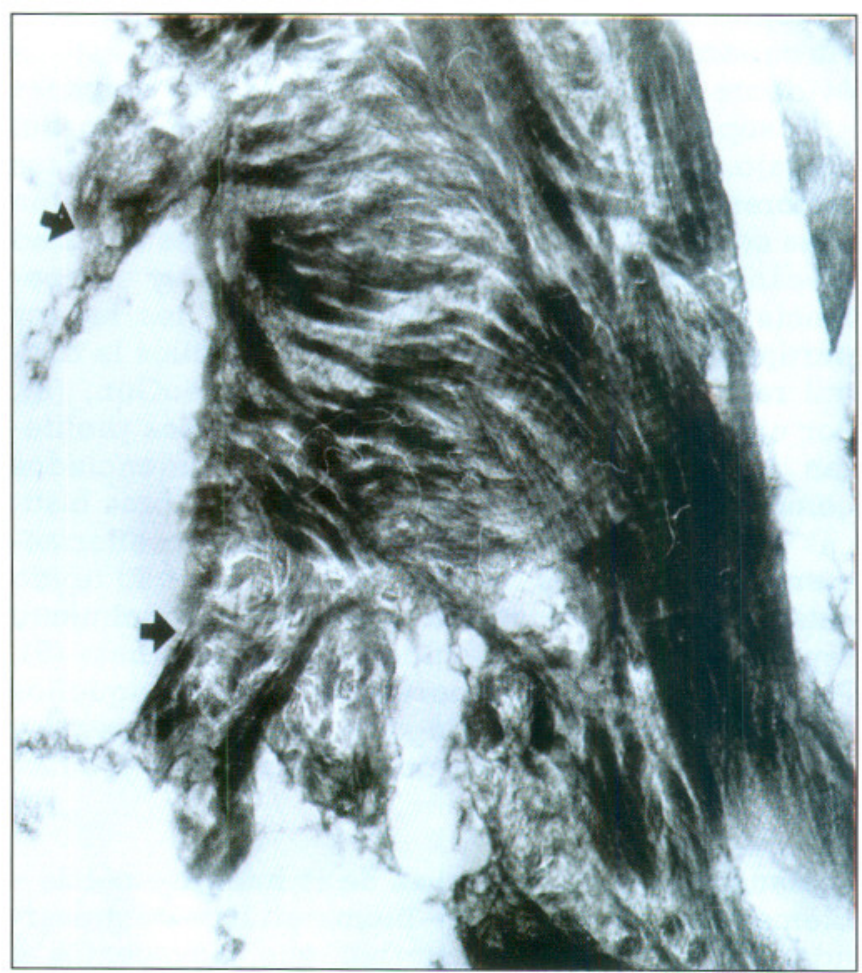

Fig. 12: Aumento original 20000x, Mayor aumento de la foto anterior en la cual claramente se observan las estriaciones tranversales de la fibrilla de colágeno en el interior de las partículas. 
características físicas actúa como andamiaje en torno al cual se realizan los procesos de osificación (9), adquiere notoria relevancia para el OsteoGen ${ }^{\oplus}$, bajo las condiciones experimentales del presente estudio ya que esta propiedad se observó claramente en las muestras obtenidas a los seis meses y a los doce meses. Nuestras observaciones corrobora el hallazgo de Ricci et al. (4) que observó en el OsteoGen ${ }^{\circledast}$, a los doce semanas de implantando en tibia de perro, una intensa actividad osteogénica y osteoconductora. Por otra parte, Whittaker et al., en biopsias de OsteoGen ${ }^{\circledast}$, injertado en seno maxilar humano obtenidas a los seis meses, observaron nuevo hueso rodeando a las partículas (5). Con respecto a nuestros resultados y bajo estas condiciones experimentales, las partículas más próximas a la superficie radicular demostraban menos formación ósea que aquellas que si se encontraban en relación directa a las paredes del defecto óseo remanente. Esto se debe, en primer lugar, a la mejor ubicación de algunas partículas que adaptándose a las anfractuosidades de las paredes óseas remanentes, permiten la colonización de células osteoprogenitoras provenientes de la médula ósea adyacente, que serían las primeras en colonizar al material facilitando de este modo la formación de tejido osteoide. Además, probablemente parte del material implantado, es decir el más alejado del hueso, es colonizado por células no-osteogénicas, capaces de formar un tejido conjuntivo fibroso (Conectivo conducción) sin capacidad de diferenciarse a tejido óseo, esto es evidente especialmente en las áreas más cercanas a la superficie radicular o al tejido conectivo del colgajo. En este sentido, conociendo los distintos factores que impiden o previenen la reparación ósea como fallas en la vascularización, inestabilidad mecánica, tamaño de los defectos óseos y competencia en la actividad proliferativa de los tejidos partipantes, probablemente se deba a ellos la disímil respuesta osteoconductiva del OsteoGen, (9). Por ejemplo los tejidos conectivos fibrosos proliferan más rápido que los altamente diferenciados como es el tejido óseo, organizando barreras hísticas en el sitio de las lesión y retardando enormemente los procesos de regeneración ósea. El tejido ósteoide puede competir con ellos y finalmente reparar, pero a una velocidad mucho más baja (9). Por lo anterior es la importancia de todos aquellos medios físicos y/o biológicos que promuevan y soporten la regeneración ósea (membranas y/o factores de crecimiento).

La naturaleza y las funciones de la interfase célula biomaterial / tejido óseo - biomaterial es controvertida. Mazzotti et al., describió que, adyacentes a implantes de titanio una capa de 30 a 50 micrones de ancho, compuesta de fibras colágenas inmaduras ricas en glicosaminoglicanos, en la interfase hueso- titanio (13), Gross et al., indican que en la interfase de un cerámico vítreo, previo a la calcificación su ubica un material granular que posteriormente se hipercalcifica (10). Davies et al., afirma que en la superficie del implante Calcitite se deposita un sustrato en el cual se insertan las fibras colágenas de la matriz extracelular calcificada (11). Holtgrave et al., demuestran una banda fina afibrilar y granular en interfases tisulares-partículas de Osprovit, e Interpore-200 (14). En estudios de Kenney et al., sólo se observan fibras colágenas recorriendo el tejido óseo recién organizado sin ninguna capa amorfa interpuesta con el material de estudio (Interpore200) (12). Albrektsson et al., reconocen una zona inmediata a implantes de titanio compuesta principalmente de proteoglicanos y de un grosor de 20 a $40 \mathrm{~nm}$ (15), sin embargo Listgarten et al., no identifican dicha zona, describiendo un íntimo contacto entre los cristales de hidroxiapatita de la matriz ósea y la superficie de titanio sin evidencia alguna de una zona no mineralizada (16). En el presente estudio se observa que la interfase entre el OsteoGen ${ }^{\circledast}$, y el tejido óseo puede adoptar distintas modalidades, así es posible visualizar ultraestructuralmente en la interfase una banda granular - amorfa de grosores variables. La MET reveló también que las partículas incluidas en el tejido óseo no presentaron una interfase definida, observándose fibrillas de colágeno de la matriz ósea en contacto directo con ellas y en los espacios intercristalinos; estos hallazgos evidenciarían que la osteoconducción además involucra una microcolonización de los espacios intercristalinos de las partículas de OsteoGen ${ }^{\circledast}$.

Los Proteoglicanos adoptan en las matrices extracelulares la imagen ultraestructural de asociaciones de elementos granulares y / o filamentosos (3). La estrecha similitud estructural entre lo anterior con la interfase OsteoGen ${ }^{\circledast}$, - hueso detectada nos hace suponer que complejos proteína- polisacaridos (Proteoglicanos ) mediatizarían la interacción hueso - biomaterial en el presente estudio. La utilización de técnicas inmunocitoquímicas es necesaria para corrobar esta suposición.

La bioreabsorción del OsteoGen ${ }^{\circledR}$, es un proceso que al parecer bajo estas condiciones experimentales se está realizando activamente dado que se observó la presencia de células mono o multinucleadas en relación con el material. Este hecho ha sido descrito anteriormente ya que varios tipos de implantes biocerámicos son reabsorbidos por células mono y/o multinucleadas. Es así como Bowell et al., observan en cultivos celulares que los osteoclastos reabsorben superficies de materiales cerámicos creando extensas lagunas (17). Klein et al., afirma que es difícil diferenciar in situ entre una célula gigante a cuerpo extraño y un osteoclasto, y que sólo una aproximación histoenzimático 
podría discriminarlo (18). Por esta razón nos referimos a células fagocíticas mono o multinucleadas. Osborn et al., agrega que las primeras células en adherirse a las superficies cerámicas son fagocitos mononucleares que la preparan para la Osteogénesis (19). En segundo lugar en nuestros especímenes la reabsorción ocurre en pequeñas excavaciones que poseen la misma apariencia que las lagunas de Howship resultante de la actividad osteoclástica descritas por Nery et al. (20), Hoogendoor et al. (21), Klein et al. (18), y Flattey et al. (22) Como esta reabsorción superficial localizada, según Arnett et al. (23), es el proceso que inicia la formación de tejidos mineralizados y siempre precede a la formación ósea alrededor del material injertado, esta fase probablemente es fundamental para a histointegración de OsteoGen ${ }^{\circledast}$.

Este hecho no fue detectado en nuestro estudio ya que luego de 6 a 12 meses post-implantación, las partículas no se reabsorbieron. Ricci et al. (4), reportó en perros que aproximadamente un $80 \%$ de las partículas de OsteoGen ${ }^{2}$, se reabsorbe a las 12 semanas. Wagner JR. (7), en un reporte de caso en humanos, comprueba histológicamente a los doce meses la presencia de células fagocíticas similares a macrófagos y/ o células gigantes en la superficie de partículas de OsteoGen ${ }^{\oplus}$. Esto se debe probablemente a que el proceso reparativo en humanos es cualitativamente diferente y mucho más lento de lo que se piensa. Por otro lado Saffar JL et al. (24), afirma teoricamente que todo biomaterial después de su implantación puede reabsorberse mediante un proceso de disolución fisiológica y/o un fenómeno celular fagocítico dependiente. Cual de los dos predomina aún no se ha determinado, pero si está claro para el OsteoGen ${ }^{\oplus}$, en este sentido que existe una fuerte respuesta celular mediatizada por células mono-multinucleadas.

Reconociendo las limitaciones de este trabajo expresadas en el bajo número de muestras válido es seguir investigando con este $u$ otros materiales en animales de experimentación y humanos, las propiedades clínicas e histológicas y corroborar las cualidades presentadas y demostradas por los fabricantes.

\section{SUMMARY}

OsteoGen ${ }^{\circledast}$, has been widely used as osteoconductor material in periodontal surgery. Neverthelees the structural characteristic of the interfase and neoformated bone have scarcely assessed in human being. In order to be able to study the quality of the bone repairing around OsteoGen ${ }^{\oplus}$, the material was grafted in bone defects in two patients. The biopsies were taken after 6 months and 12 months and processed for optical microscopy (mo) and electronic transmission (met). The results with mo after 6 months show a clear osteoconduction, which is noticiable at 12 months in practically all the particles.

\section{KEY WORDS}

Bone, periodont, biomaterial, graft, osteogenesis, aloplastic.

\section{CORRESPONDENCIA}

Prof. Dr. Cristián López Valenzuela

Avenida 11 de Septiembre 1945 oficina 511

Providencia, Santiago de Chile, CHILE.

Teléfonos 2443461-2443462

Número de Fax: 2099676

E mail: drclv@entelchile.net

\section{BIBLIOGRAFÍA}

1. Hürzeler MB, Quiñones CR, Schüpbach P, Morrison EC, Caffesse RG: Treatment of peri-implantitis using guided bone regeneration and bone graft, alone or in combination, in Beagle dogs. Part 2: Histologic findings Int J Oral Maxillofac Implants 1997; 12: 168-175.

2. Hürzeler MB, Quiñones CR, Morrison EC, Caffesse RG: Treatment of peri-implantitis using guided bone regeneration and bone graft, alone or in combination, in Beagle dogs. Part 1: Clinical finding and histologic observations Int J Oral Maxillofac Implants 1995; 10: 474-484.

3. Hunziben E, Schenk R: Structural organization of proteoglycans in cartilage in Biology of Extracellular Matrix. En "A series, Biology of Proteoglycans." Ed Wight T and Mecham R. Academic Press, Inc. 1987.

4. Ricci JL, Blumenthal NC, Spivak JM, Alexander H: Evaluation of a low - temperature calcium phosphate particulate implant material: Physical - Chemical properties and in vivo bone response: J Oral Maxillofac Surg 1992; 50: 969 - 978 .

5. Wittaker JM, James RA, Lozada J, Cordova C, Garey DJ: Histological response and clinical evaluation of heterograft and allogragt material in the elevation of the sinus for the preparation of endosteal dental implant sites. Simultaneous sinus elevation and root form implantation: An eight - month autopsy report: J Oral Implantol 1989; XV: $141-144$.

6. Vlassis JM, Hürzeler MB, Quiñones CR: Sinus lift augmen- 
tation to facilitate placement of nonsubmerged implant. A clinical and histological report : Practical Periodontics and Aesthetic Dentistry 1993; 5: $15-23$.

7. Wagner JR: A clinical and histological case study using resorbable hidroxylapatite for the repair of osseous defect prior to endosseous implant surgery: J Oral Implantol 1989; XV: 186 - 192.

8. Corsair A: A clinical evaluation of resorbable hidroxylapatite for the repair of human intraosseous defect: J Oral Implantol 1990; XVI: 125 - 128.

9. Schenk RK: Bone Regeneration: Biologic Basis. Chapter Three. En Buser D, Dahlin C, Schenk RK eds. "Guided Bone Regeneration in Implant Dentistry." Quintessence Publishing Co, Inc.; 1994: 50 - 100.

10. Gross U, Brandes J, Strunz V, Bab I, Sela J: The ultrastructure of the interface between a glass ceramic and bone: J Biomed Mater Res 1981; 15: 291.

11. Davies JE, Matsuda T: Extacellular matrix production by osteoblasts on bioctive substrata in vitro: Scanning Microsc 1988; 2: 1445.

12. Kenney EB, Lekovic V, Sa Ferreira JC, Han T, Dimitrijevic B, Carranza Jr FA : Bone formtion within porous hidroxylapatite implants in human periodontal defects: J Periodontol 1986; 57: $76-83$.

13. Mazzotti G, Ruggeri A, Ottaini V, Maraldi NM: Ricerche istochimiche ed ultrastrutturali sul consolidamento dell'impianto endosseo dentario in Macacus Fascicularis: Minerva Stomatol 1984; 33: 405.

14. Holtgrave EA: Attachment of cementum on different hidroxylapatite ceramic ( $\mathrm{HAC}$ ) substrata in vivo. A light and electron microscopic study: J Periodont Res; 26: 511 - 518.
15. Albrektsson T, Hansson HA, Ivarsson B: Interface analysis of titanium and zirconium bone implants: Biomaterials 1985; 6: 97 - 101.

16. Listgarten MA, Buser D, Steinemann S, Donath K, Weber HP, Lang NP: Light and transmission electron microscopy of the intact interface between bone, gingiva and nonsubmerged titanium -coated epoxy resin implants: J Dent Res 1992; 71:364-371.

17. Bovell Y, Davies JE, Tarrant S: Incident light and SEM observation of bone cell colonized bioceramics: Histochem J 1986; 18: 583.

18. Klein CPAT, Driessen AA, van der Hoof $A$ : Biodegradation behavior of various calcium phosphate materials in bone tissue: J Biomed Mater Res 1983; 17: 769.

19. Osborn JF: Implantatwerkstoff Hydroxylapatitkeramik. Berlín: Quintessenz Verlag GmbH 1985; 127-176, 29-40.

20. Nery EB, Lynch KL, Hirthe WM, Mueller KH: Bioceramics implants in surgically produced infrabony defects: J Periodontol 1975; 46: 328.

21. Hoogendoorn HA, Renooij W, Akkermans LMA, Visser W, Wittebol P: Long-term study of large ceramics implants in dog femora : Clin Orthop Rel Res 1984; 187: 281.

22. Flattey TJ, Lynch $\mathrm{KL}$, Benson $\mathrm{M}$ : Tissue response to implants of calcium phosphate ceramics in the rabbit spine: Clin Orthop Rel Res 1983; 179: 246.

23. Arnett, RA : Update on bone cell biology: Europ J Orthod 1990; 12: 81- 90.

24. Saffar JL, Coloombier ML, Detienville R: Bone formation in tricalcium phosphate - filled periodontal intrabony lesion. Histological observation in Human. J Periodontol 1990; 61: 209-216. 